\title{
White Matter Changes in Corpus Callosum in a Patient with Idiopathic Normal Pressure Hydrocephalus?
}

Sir,

I read with great interest the article by Mullaguri et al., in which they describe a normal pressure hydrocephalus (NPH) patient presenting with coma after quetiapine and trazodone overdose, at whom cranial magnetic resonance imaging showed diffuse corpus callosum T2 hyperintensity. ${ }^{[1]}$ They associated the neuroimaging changes with shunt surgery for NPH and gave some crucial insights for clinical concerns. ${ }^{[1]}$ I appreciate the authors for pointing out this interesting patient and for constituting impressive discussions. However, I would like to comment on some aspects for a better understanding of the issue and also, in the light of the related literature data, I would like to suggest some new discussions for further clarifications in this regard.

First, a major point to be discussed is that $\mathrm{T} 2$ hyperintense changes in the corpus callosum are a recognized entity in obstructive hydrocephalus subtypes but rather atypical in communicating hydrocephalus. ${ }^{[2,3]}$ In accordance with this knowledge, it has been explained to develop in the setting of long-standing mechanical compression by the falx cerebri, rather encountered in obstructive hydrocephalus. Such that, in a crucial study, Spreer et al. associated the presence of callosal hypodensity with "forced ventricular drainage" emphasizing the altering pressure dynamic in ventricular systems. ${ }^{[4]}$ Furthermore, Lane et al. emphasized that they had not observed any of the callosal signal changes in patients with communicating forms of hydrocephalus. ${ }^{[3]}$ Hence, I think that while associating the callosal hyperintensity with ventriculoperitoneal (VP) shunting in a patient with $\mathrm{NPH}$, a meticulous evaluation needs to be conducted. Based on the presentation of this case, the diagnosis of toxic encephalopathy associated with drug overdosage and related callosal changes cannot be excluded. Remarkably, diffusion-weighted imaging (DWI) data, which is a crucial tool for understanding the nature of lesion of corpus callosum, ${ }^{[5,6]}$ were not mentioned in the report constituting a major limitation. For instance, high signal in DWI might rather suggest an underlying toxic encephalopathy. ${ }^{[6]}$

Second, the authors described the callosal changes as occurring due to VP shunting for the NPH (in the abstract section). It has been pointed out that signal alterations of corpus callosum can be seen in patients scanned after shunting for obstructive hydrocephalus. ${ }^{[3]}$ Although the mechanism of the development of this neuroimaging sign is not exactly clarified, these changes were mainly explained to be secondary to long-standing hydrocephalus, rather than the effect of shunt surgery primarily. ${ }^{[7]}$ Hence, I think that this statement in the 
abstract section ${ }^{[1]}$ may cause misleading conclusions associating the callosal changes with primarily the effect of shunt surgery.

Another interesting point in this regard may be that, as also the authors mentioned, mechanical compression by the falx cerebri resulting in ischemic demyelination was a major hypothesis to explain these neuroimaging changes. ${ }^{[3,4,7]}$ However, no clinical signs those might be attributed to callosal malfunction were seen in these patient groups..$^{[1,3,4,7]}$ In my opinion, considering that no any malfunction of corpus callosum is present in these patients, explaining these lesions as "ischemic injury" [3] based on solely a neuroimaging finding of T2 hyperintensity may be irrational. I think that defining these changes as a neuroimaging sign of altering pressure dynamics in these patient subgroups might be more rational. In the light of this hypothesis, another question may that why these changes are rather seen in postshunt obstructive hydrocephalus patients in comparison to communications' hydrocephalus patients. In addition, other questions to be asked are may there specific clinical parameters discriminating these minority ratios of NPH patients with callosal hyperintensity from others? or may this radiological finding be a marker in understanding the processing pressure gradients in hydrocephalus and even in the prediction of the prognosis of the patients? Results of future prospective studies as well as valuable case illustrations such as Mullaguri et al. are warranted to clarify these questions. Specifically, functional neuroimaging studies may add substantial contributions to our understanding of this mysterious neuroimaging sign in hydrocephalus patients.

\section{Financial support and sponsorship}

Nil.

\section{Conflicts of interest}

There are no conflicts of interest.

Halil Onder

Department of Neurology, Neurology Clinic, Yozgat City Hospital, Yozgat, Turkey
Address for correspondence: Dr. Halil Onder, Neurology Clinic, Yozgat State Hospital, Yozgat, Turkey. E-mail: halilnder@yahoo.com

\section{REFERENCES}

1. Mullaguri N, Battineni A, Newey CR, Nattanmai P. White matter changes in corpus callosum in a patient with idiopathic normal pressure hydrocephalus. J Neurosci Rural Pract 2017;8:657-9.

2. Badía MC, Bueno A, Láinez JM. Corpus callosal signal changes in patient with obstructive hydrocephalus after ventriculoperitoneal shunting. Neurologia 2005;20:692-3.

3. Lane JI, Luetmer PH, Atkinson JL. Corpus callosal signal changes in patients with obstructive hydrocephalus after ventriculoperitoneal shunting. AJNR Am J Neuroradiol 2001;22:158-62.

4. Spreer J, Ernestus RI, Lanfermann H, Lackner K. Lesions of the corpus callosum in hydrocephalic patients with ventricular drainage - A CT-study. Acta Neurochir (Wien) 1996;138:174-8.

5. Ren $\mathrm{S}$, Chen Z, Liu M, Wang Z. The radiological findings of hypoglycemic encephalopathy: A case report with high $b$ value DWI analysis. Medicine (Baltimore) 2017;96:e8425.

6. Park SE, Choi DS, Shin HS, Baek HJ, Choi HC, Kim JE, et al. Splenial lesions of the corpus callosum: Disease spectrum and MRI findings. Korean J Radiol 2017;18:710-21.

7. Numaguchi Y, Kristt DA, Joy C, Robinson WL. Scalloping deformity of the corpus callosum following ventricular shunting. AJNR Am J Neuroradiol 1993;14:355-62.

This is an open access journal, and articles are distributed under the terms of the Creative Commons Attribution-NonCommercial-ShareAlike 4.0 License, which allows others to remix, tweak, and build upon the work non-commercially, as long as appropriate credit is given and the new creations are licensed under the identical terms.

\begin{tabular}{|l|l|}
\hline \multicolumn{2}{|c|}{ Access this article online } \\
\hline Quick Response Code: & Website: \\
\hline
\end{tabular}

How to cite this article: Onder $\mathrm{H}$. White matter changes in corpus callosum in a patient with idiopathic normal pressure hydrocephalus? J Neurosci Rural Pract 2018;9:439-40.

(c) 2018 Journal of Neurosciences in Rural Practice | Published by Wolters Kluwer - Medknow 